\title{
La huella de la Real Academia Española en manuales de enseñanza de la lengua para la Educación Secundaria
}

\author{
Antonio Gutiérrez Riveroi] \\ Universidad de Cádiz, Cádiz, España \\ Victoriano Gaviño Rodríguezii \\ Universidad de Cádiz, Cádiz, España
}

\begin{abstract}
Resumen
Este estudio se centra en el análisis de algunos de los materiales didácticos utilizados en la escuela de español para la enseñanza del idioma. Se pretende analizar la organización y presentación del contenido gramatical de estos manuales, así como el estudio de enfoques metodológicos y actividades desarrolladas en relación con un contenido específico, el concepto de oración, presente en todos los manuales del $4^{\circ}$ de la Educación Secundaria Obligatoria de muestra seleccionada. El resultado de este estudio nos permitirá sacar conclusiones generales sobre el proceso actual de enseñanza y aprendizaje de esta disciplina en la escuela en España, así como demostrar la marca que las gramáticas escolares publicadas por Real Academia Española desde mediados del siglo XIX ha dejado en estos materiales, a través de una metodología de la enseñanza que, aunque intenta adoptar los avances de la lingüística teórica y aplicada, está al mismo tiempo anclada en un estatismo didáctico que se observa incluso en las prácticas docentes de la facultad misma.
\end{abstract}

Palabras clave

RAE. Enseñanza de la lengua. Educación Secundaria.

\section{A marca da Real Academia Espanhola nos manuais de ensino da língua para o Ensino Secundário}

\begin{abstract}
Resumo
Este estudo se concentra na análise de alguns dos materiais didáticos utilizados na escola espanhola para o ensino da língua. Pretende-se analisar a organização e apresentação do conteúdo gramatical desses manuais, bem como o estudo de abordagens metodológicas e atividades desenvolvidas em relação a um conteúdo específico, o conceito de oração, presente em todos os manuais da $4^{\text {a }}$ série do Ensino Secundário Obrigatório da amostra selecionada. O resultado deste estudo nos permitirá tirar conclusões gerais sobre o atual processo de ensino e aprendizagem dessa disciplina na escola na Espanha, bem como demonstrar a marca que as gramáticas escolares publicadas pela Real Academia Espanhola desde meados do século XIX deixou nesses materiais, através de uma metodologia de ensino que, embora tente adotar os avanços da linguística teórica e aplicada, está ao mesmo
\end{abstract}

Educ. Form., Fortaleza, v. 5, n. 3, e2891, set./dez. 2020

DOI: https://doi.org/10.25053/redufor.v5i15set/dez.2891

https://revistas.uece.br/index.php/redufor/index 
tempo ancorada em um estatismo didático que é observado até mesmo nas práticas docentes acadêmicas.

\title{
Palavras-chave
}

RAE. Ensino de língua. Ensino Secundário.

\section{The mark of the Royal Spanish Academy in language teaching manuals for Secondary Education}

\begin{abstract}
This study focuses on the analysis of some of the didactic materials used in the Spanish school for language teaching. It is intended to analyze the organization and presentation of the grammatical content of these manuals, as well as the study of methodological approaches and activities developed in relation to a specific content, the concept of prayer, present in all the manuals of the 4th series of Compulsory Secondary Education in the sample. selected. The result of this study will allow us to draw general conclusions about the current teaching and learning process of this discipline at school in Spain, as well as to demonstrate the mark that the school grammars published by the Spanish Royal Academy since the middle of the 19th century left in these materials, through a teaching methodology that, although it tries to adopt the advances of theoretical and applied linguistics, is at the same time anchored in a didactic statism that is observed even in academic teaching practices.
\end{abstract}

Keywords

RAE. Language teaching. High school.

\section{La influencia de la Real Academia de la Lengua Española en la escuela}

El debate acerca de la conveniencia de "aprender lengua" o "aprender a hacer cosas" teniendo como base la lengua no es reciente. Desde hace mucho tiempo se discute sobre el valor de la educación y, en concreto, sobre la importancia que el estudio de la lengua tiene en el desarrollo de los individuos y la construcción identitaria de la nación. Este tema fue muy frecuente y una de las dialécticas más recurrentes entre conservadores y liberales en la España del XIX o en el seno de la construcción de las repúblicas americanas, con numerosos debates acerca de la importancia o no del estudio de la lengua materna como elemento vertebrador para el desarrollo de los individuos, y, aún hoy día, abundan los trabajos especializados que siguen profundizando en este aspecto, especialmente, en el plano pedagógico en relación con la diversidad lingüística de los distintos territorios (MARTín ROJO, 2003). 
Al hilo de estas ideas, vienen a nuestra mente unas palabras del propio Unamuno (1958b, p. 634) que podrían ser válidas aún hoy día, cuando, en una conferencia de 1905, afirmaba que la más exacta definición de la gramática era la de aquel muchacho que, al preguntársele “¿Qué es Gramática?”, contestaba “Ese libro que está ahí". Unamuno (1958b), que ya en otras ocasiones había mostrado su antiacademicismo, no hace otra cosa con sus palabras que criticar los métodos docentes impuestos por la Real Academia Española en la escuela. También, precisaba aún más su crítica respecto a la enseñanza de la lengua y los problemas originados por este sistema de enseñanza basado exclusivamente en el etiquetado y clasificación de fenómenos gramaticales, que ya en su época estaba vigente en el análisis gramatical:

\begin{abstract}
Y en hora buena ¿cree nadie en serio que el aprender si a una palabra ha de clasificársela como simple o compuesta, primitiva o derivada, colectiva o partitiva, enseña a nadie a usarla con mayor corrección y propiedad? ¿Cree nadie que así se aprende a hablar bien? ¿No se ve bien claro que todo ello no es sino clasificar por clasificar, sin ulterior validez de la clasificación? (UNAMUNO, 1958b, p. 637).
\end{abstract}

Como se aprecia, la discusión sobre la forma de enseñar la lengua en la escuela estaba ya muy presente en el el siglo pasado. En efecto, el gran mal de la gramática, frente a otras materias, es que esta se concibe de manera ajena al individuo y vinculada en exceso a una materia escolar sin repercusión alguna para la formación de las personas ni aplicación en la vida real.

La institucionalización de la enseñanza del español va a estar relacionada con la creación de la Real Academia Española de la Lengua (1713) y su progresiva institucionalización, coincidiendo con la llegada de la dinastía borbónica y los Decretos de Nueva Planta, que suponen la creación de un Estado centralizado y el fomento de una lengua común. A mediados del siglo XVIII en España se comenzó a regular el sistema de enseñanza de la lengua materna por medio de una serie de leyes que, desde la Corona, daban preferencia a los textos y métodos impuestos por la institución, que desde su fundación había ido consolidando su prestigio por medio de las distintas ediciones de sus proyectos de Diccionario, Ortografía y Gramática, sacadas a la luz a lo largo del siglo XVIII y primera mitad del XIX.

Este apoyo legislativo a la corporación culmina en 1857, cuando los textos de la Academia se convierten en oficiales por medio de la Ley de Instrucción Pública (conocida como Ley Moyano, publicada el 9 de septiembre de 1857), cuyo artículo 88 
declara la Gramática y la Ortografía de la Academia Española como texto obligatorio y único para estas materias en las escuelas de enseñanza pública, sentando así las bases de la doctrina de esta institución en la enseñanza de la lengua e incrementando notablemente la influencia que, ya desde el siglo anterior, venía ejerciendo la institución en otros gramáticos. A partir de esta fecha, la Real Academia Española llevó a cabo ediciones oficiales del texto gramatical con una mayor regularidad en 1858, 1862, $1864,1865,1866,1867$, etc., con las que intentaba dar respuesta a la demanda generada, pero también nacieron las publicaciones del Epítome y el Compendio, que, adaptadas a partir del texto gramatical académico, fueron destinadas a la primera y segunda enseñanzas, respectivamente (GUTIÉRREZ ORDÓÑEZ; GAVIÑO RODRÍGUEZ, 2014, p. 339). Estas dos obras fueron editadas continuamente desde 1857 para cumplimiento de la Ley de Instrucción Pública. La vigencia de estos textos académicos en las escuelas se vio reforzada por leyes posteriores en 1873 y 1895, aunque, a partir de 1926 - citamos a Zamora Vicente (1999, p. 404, nota 14) -, empezó a cuestionarse este papel y, a mitad del siglo XX, la Academia ya no editó ninguna gramática destinada al uso escolar.

En 2010, sin embargo, la Real Academia Española publicó la versión manual de su Nueva gramática de la lengua española (2009). La pérdida de estos textos académicos escolares no ha mermado, sin embargo, el influjo de su doctrina, que, más allá de los avances experimentados por la gramática, la metodología de enseñanza de lenguas y los cambios legislativos en materia educativa, sigue latente en mayor o menor medida en los manuales y prácticas docentes actuales. Por otro lado, con sus distintas categorizaciones y conceptualizaciones, el término oración es quizás el de mayor repercusión en la teoría gramatical española desde finales del siglo XIX, especialmente por las nuevas teorías que las gramáticas castellanas publicadas en España comienzan a adoptar a partir de la corriente francesa.

Aunque con algo más de lentitud que en otros autores, estas nuevas tendencias pronto acaban por penetrar en las teorías de la Academia, que, desde el modelo que inaugura la edición gramatical de 1870, da un nuevo vuelco al análisis gramatical. Hasta ese momento, la gramática castellana se centraba de manera clara en el análisis de las partes de la oración, esto es, las distintas categorías o clases de palabras, desdeñando el estudio oracional (GARCíA FOLGADO, 2014, p. 68). En 
cualquier caso, desde la primera edición gramatical de 1771 de la Real Academia Española, se usa el término oración en la descripción gramatical de la lengua, si bien no es hasta 1870, cuando, adoptando tendencias ya presentes en otras obras no académicas, este comienza a cobrar especial sentido en la teoría de la corporación, una vez que la oración aparece claramente categorizada y definida, con distintas clasificaciones y subtipos que irán modificándose a lo largo de las distintas publicaciones del libro de gramática. Pero es en 1917 cuando la gramática académica, inaugurando su sexto modelo, da un gran cambio hacia una tendencia sintacticista así lo ha manifestado Gómez Asensio (2011, p. 1917) - con “[...] el abandono de las viejas estructuras y la re-inserción en la modernidad gramatical”. Es en esta edición donde se produce la incorporación de nueva terminología y conceptos y se adopta en gran medida las tradicionales clasificaciones que hoy día perduran (con escasas modificaciones) en muchos manuales de gramática de nuestra lengua para las clasificaciones de la oración.

A partir del análisis de un contenido concreto, el de la oración, intentaremos poner de relieve en este estudio la influencia de los textos gramaticales académicos en los materiales didácticos usados en la escuela actualmente. El objeto final del trabajo consistirá, así pues, en analizar críticamente el proceso actual de enseñanza y aprendizaje de esta materia en la escuela, así como evidenciar con datos el funcionamiento del uso de una metodología docente que, por un lado, intenta beber de las evoluciones y avances de la lingüística teórica y aplicada, pero, por otro lado, recibe el influjo de una tradición escolar en la que la evolución de los sistemas educativos y legislaciones no consigue vencer el estatismo en el que nos ha sumido la Real Academia Española como órgano regulador de la materia y formadora de los propios docentes.

\section{Corpus de la investigación}

Nuestro estudio partirá del análisis de un total de nueve libros de texto de $4^{\circ}$ curso de Educación Secundaria Obligatoria ${ }^{1}$ de diferentes editoriales y autores, todos ellos

${ }^{1}$ Se trata del cuarto y último curso de la Educación Secundaria Obligatoria en España, que sucede a la Educación Primaria y da paso a los dos cursos de Bachillerato, por lo que se trata del curso final de ciclo. La edad de los alumnos corresponde a los 16 años.

Educ. Form., Fortaleza, v. 5, n. 3, e2891, set./dez. 2020

DOI: https://doi.org/10.25053/redufor.v5i15set/dez.2891

https://revistas.uece.br/index.php/redufor/index 
usados en un total de 20 centros de enseñanza públicos y privados de la ciudad de Sevilla, que son objeto de una investigación mayor completada con el estudio de las creencias de parte de su profesorado $(n=20)$ y alumnado $(n=447)$. Esos otros elementos de la triangulación son tratados en otra publicación y aquí nos centraremos en el análisis de los libros de texto. Partiendo del modo de proceder de otros trabajos que en los últimos años han centrado también su análisis en los libros de texto y su uso en la enseñanza de la lengua (FERRER, 2015; GIETZ, 2019; JIMÉNEZ FERNÁNDEZ, 2011; RIBAS, 2010, entre otros), esta investigación centra su atención en la siguiente muestra de materiales docentes (a las que en adelante haremos alusión por el nombre de la editorial):

Tabla 1 - Selección de libros analizados

\begin{tabular}{|c|c|c|c|c|}
\hline Autor & Año & Título & Ciudad & Editorial \\
\hline $\begin{array}{l}\text { Alsina, R.; Fortuny, J.; Martí, S.; } \\
\text { Picó, C. }\end{array}$ & 2008 & $\begin{array}{l}\text { Lengua castellana y Literatura } \\
4^{\circ} \text { de ESO }\end{array}$ & Madrid & Teide \\
\hline $\begin{array}{l}\text { Andrés, P.; González, M.; } \\
\text { Jiménez, M. }\end{array}$ & 2011 & Leng_04. Aula $360^{\circ}$ & Zaragoza & Edelvives \\
\hline Bazarra, L.; Casanova, O. & 2011 & $\begin{array}{l}\text { Lengua Castellana y Literatura } \\
\qquad 4^{\circ} \text { de ESO }\end{array}$ & Madrid & SM \\
\hline $\begin{array}{l}\text { Gómez, J.; Lajo, J.; Toboso, J.; } \\
\text { Vidorreta, C. }\end{array}$ & 2011 & $\begin{array}{c}\text { Lengua Castellana y Literatura. } \\
4^{\circ} \text { de ESO Andalucía }\end{array}$ & Zaragoza & Bruño \\
\hline $\begin{array}{l}\text { González, J. A. (Coord.), Ariza, } \\
\text { J.; Coca, I.; Hoster, B.; Ruiz, A. }\end{array}$ & 2008 & $\begin{array}{c}\text { Lengua Castellana y Literatura. } \\
4^{\circ} \text { de ESO (Andalucía) }\end{array}$ & Sevilla & Algaida \\
\hline $\begin{array}{c}\text { Juan, E. (Dir.), Bustamante, L.; } \\
\text { Cicuéndez, L.; Ferro, E.; López, } \\
\text { P.; López, F.; Rojo, P. }\end{array}$ & 2011 & Lengua y Literatura $4^{\circ}$ de ESO & Sevilla & $\begin{array}{l}\text { Santillana } \\
\text { Grazalema }\end{array}$ \\
\hline López, F.; Serrano, S. & 2008 & $\begin{array}{c}\text { Lengua castellana y Literatura } \\
4^{\circ} \text { de Secundaria }\end{array}$ & Madrid & $\begin{array}{c}\text { Oxford } \\
\text { Educación }\end{array}$ \\
\hline Navarro, E.; Reina, A. & 2011 & $\begin{array}{l}\text { Lengua Castellana y Literatura } \\
4^{\circ} \text { de ESO }\end{array}$ & Barcelona & Casals \\
\hline VVAA & 2008 & Lengua y Literatura $4^{\circ}$ de ESO & Sevilla & $\begin{array}{l}\text { Guadiel- } \\
\text { Grupo } \\
\text { Edebé }\end{array}$ \\
\hline
\end{tabular}

Fuente: Elaboración propia (2020).

Dado el carácter de este trabajo, centraremos nuestro interés en dos aspectos de estos manuales: en primer lugar, el examen de la estructura y la disposición de contenidos en la obra; posteriormente, el análisis de la tipología de actividades propuesta en relación con uno de los conceptos fundamentales y por lo general presente en todos estos manuales de enseñanza de la lengua, el de oración, con respecto al cual examinaremos, además, los distintos planteamientos y nivel de profundidad con que se aborda su estudio. Nos decantamos por este concepto por su interés en el análisis gramatical y la sospecha de que sea el elemento nuclear de la transposición didáctica, 
heredera del estructuralismo (GIETZ, 2019). Los resultados de esta investigación nos permitirán extraer conclusiones generales acerca del trasvase que estos libros llevan a cabo partiendo de la legislación.

En líneas generales, el análisis de los manuales seleccionados constata una realidad previamente sospechada: ninguno se ajusta exactamente a los cambios metodológicos que las leyes educativas pretendían para la enseñanza de la lengua y, específicamente, de la gramática. Aunque existen ciertos intentos de cambio (al menos en lo referente a la inclusión de cierta tipología de ejercicios y de textos), ninguno de ellos se centra de manera global (sí de forma aislada) en la adquisición de las habilidades instrumentales ni desplaza los saberes teóricos al papel de herramienta con la que lograr esas habilidades. Esta observación se hace palpable con la mera revisión de los índices de los manuales, que nos revela que los contenidos de teoría gramatical siguen siendo parte importante en el estudio de la lengua, pues estos son concebidos per se como finalidad educativa, es decir, como saberes teóricos sin conexión alguna con la práctica de la competencia comunicativa a la que la legislación sí hace referencia (ESPAÑA, 2007, p. 730-731). Esta afirma que: "[...] el eje del currículo son las habilidades y estrategias para hablar, escribir, escuchar y leer en ámbitos significativos de la actividad social", que se recogen en cuatro bloques de contenidos en el currículo (1. Hablar, escuchar y conversar; 2. Leer y escribir; 3. Educación literaria; 4. Conocimiento de la lengua), de los cuales este último sirve para reunir "[...] los contenidos que se refieren a la capacidad de los alumnos para observar el funcionamiento de la lengua y para hablar de ella, así como a los conocimientos explícitos sobre la lengua y sus formas de uso" (ESPAÑA, 2007, p. 730731). Es esa actividad metalingüística la que debe abrir paso a establecer la relación entre los conceptos gramaticales y los usos lingüísticos (CAMPS, 2017, p. 29-30), pues en el terreno lingüístico todo se interrelaciona en actos comunicativos.

A pesar de que en la legislación se indica que "[...] la organización de los contenidos del currículo en estos bloques no tiene como finalidad establecer el orden y la organización de las actividades de aprendizaje en el aula" (ESPAÑA, 2007, p. 731), algunos de estos manuales toman como norma la división de los contenidos de cada unidad en relación con los siguientes bloques temáticos, más o menos subdivididos o fraccionados: a) comunicación, b) estudio de la lengua y c) literatura - Bruño, Algaida, 
Oxford, SM y Teide. Otras obras llevan a cabo una distinta secuenciación de contenidos dividiendo en lengua y literatura: Casals y Guadiel (Conocimiento de la lengua, en las primeras siete unidades, y la Educación literaria, de la unidad 8 a la 14); Edelvives divide sus 12 unidades en Lengua (unidades 1-6) y Literatura (unidades 712); y, finalmente, Grazalema Santillana posee una organización diferente: Lengua (en todas las lecciones), Comunicación (unidades 1-6) y Literatura (unidades 7-12).

Independientemente de la organización de estos contenidos, el primer bloque de comunicación en estos manuales se dedica a las cuatro destrezas, con predominio de las escritas frente a las orales, y al estudio de las tipologías textuales. Sirva como ejemplo el manual de Grazalema Santillana, que advierte en sus instrucciones iniciales que, dentro del bloque de comunicación, se abordarán aspectos relacionados con leer, escribir y hablar, pero poco más adelante podemos comprobar que se centran en las dos primeras, tal y como reza en el índice de sus unidades (cf. p. 4-5).

La mayor parte de las veces se comienza con un texto escrito, preferentemente literario (cf., por ejemplo, Algaida o SM). Aunque la tipología de autores es muy diversa y no se ciñe a los clásicos, sigue resultando bastante común el uso de ese tipo de textos. Antes de la reforma de la Ley Orgánica General del Sistema Educativo (LOGSE), predominaban los textos literarios y la mayor parte de profesores en activo corresponden a ese periodo. El segundo bloque, destinado al estudio de la lengua, integra contenidos relacionados con léxico, ortografía y morfosintaxis. Dependiendo de cada libro, se subdividen las diferentes secciones atendiendo a esas temáticas (así lo hace, por ejemplo, Bruño, dividiendo entre "Gramática", "Léxico" y "Ortografía"), o se engloba todo en un solo bloque llamado "Lengua" - Oxford, Edelvives y Algaida -, "Conocimiento de la lengua" - SM, Guadiel, Teide y Casals - o "Estudio de la lengua" - Grazalema.

Aunque en el Real Decreto no 1631/2006 se advierte que "[...] la interrelación de este bloque con el resto obliga a que la programación de las actividades relacionadas con su contenido tenga siempre una justificación desde el punto de vista de su relevancia para la mejora de las habilidades en el uso de la lengua" (ESPAÑA, 2007, p. 731), lo que en la práctica encontramos en estos libros es un apartado específico con contenidos referidos al funcionamiento de la lengua no integrados con respecto a los otros, tal y como se observa ya de antemano en los propios índices de los libros. 


\title{
2.1 Tratamiento metodológico en el "Conocimiento de la lengua": el caso de la oración como contenido gramatical
}

Intentaremos ahondar un poco más en el bloque de "Conocimiento de la lengua", que es el que se reserva para el estudio de lo que generalmente entendemos como gramática. La legislación dice lo siguiente:

\begin{abstract}
Por último, el bloque 4, Conocimiento de la lengua, integra los contenidos relacionados con la reflexión sobre la lengua y con la adquisición de unos conceptos y de una terminología gramatical. La presencia de este bloque se justifica por el hecho de que la adquisición de las habilidades lingüísticocomunicativas implica el uso reflexivo sobre diferentes aspectos de la lengua: la variación y los factores que explican dialectos, registros y usos sociales; las formas lingüísticas que indican en el texto la presencia de los factores del contexto; los procedimientos que contribuyen a cohesionar el texto; las diversas posibilidades sintácticas que son utilizables para expresar un mismo contenido; los procedimientos gramaticales para integrar diferentes proposiciones en un enunciado cohesionado; los mecanismos para la formación de palabras; la norma gramatical y ortográfica, etc. (ESPAÑA, 2007, p. 731).
\end{abstract}

A pesar de lo especificado, en los manuales revisados abundan ejercicios consistentes en la mera catalogación de fenómenos gramaticales, que en absoluto responden a una reflexión sobre el funcionamiento de la lengua y menos aún al desarrollo de habilidades lingüístico-comunicativas. Contrariamente, la actividad del alumno suele consistir en un mero ejercicio memorístico de términos y conceptos y en la identificación de determinados elementos, tal y como se demuestra, además, con la constante presencia en estos manuales de ejercicios individuales en los que solo hay que señalar diversos elementos sintácticos, tales como el sujeto, el predicado y otras funciones. Esa concepción didáctica de la gramática es achacada por Camps (2014, p. 10) a la influencia de los modelos formales de la lingüística del siglo XX. El mismo modo en el que se enuncian las actividades (con verbos como detectar, encontrar, etc.) predispone al alumno a la aplicación mecánica de una serie de saberes aprendidos sin reflexión alguna ni vinculación con el significado. Hay múltiples ejemplos en todos los manuales, pero veamos el siguiente (Imagen 1): 
Imagen 1 - Ejemplo de actividad

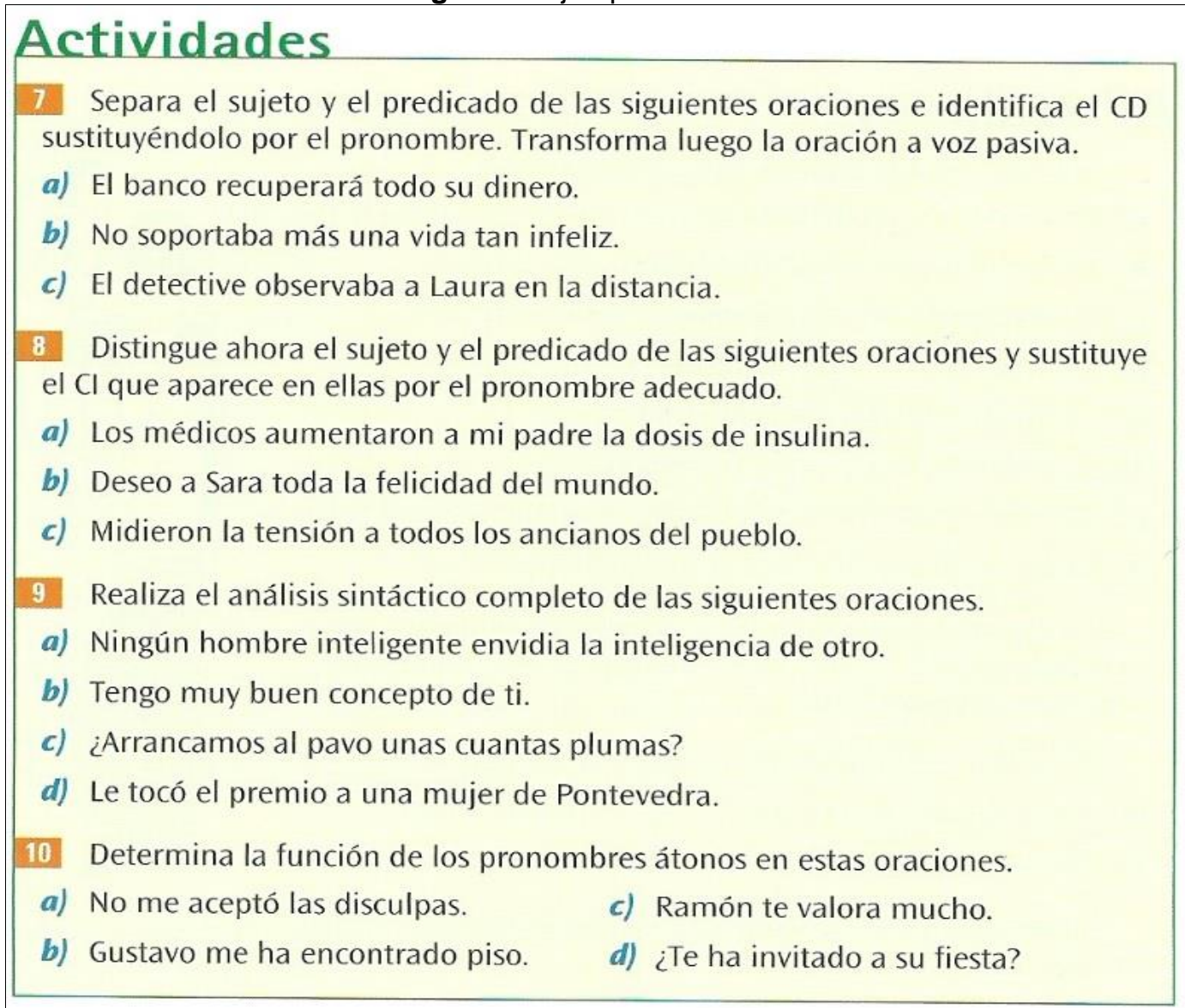

Fuente: Oxford Educación (2008, p. 34).

Si analizamos hasta qué punto en estos libros se está fomentando una enseñanza en la que el alumno pueda razonar y añadir nuevos conocimientos a los ya aprendidos anteriormente para construir su propio aprendizaje, los resultados no son muy positivos. Evidentemente, estas actividades taxonómicas no son del todo relevantes ni significativas; por otro lado, aquellas otras actividades que solo sirven para memorizar teoría gramatical parecen, al menos en ocasiones, evaluar exclusivamente la competencia de saber "cortar" y "pegar" contenidos de una frase anterior, como el caso que exponemos en la Imagen 2, donde el alumno, si quiere completar con éxito la tarea, simplemente tiene que buscar la información justamente en el enunciado de arriba sin preocuparse por entenderlo, incluso con las palabras destacadas en negrita: 
Imagen 2 - Ejemplo de actividad

\section{> Estructura del sintagma verbal}

El sintagma verbal está formado por un núcleo, que es un verbo, y puede ir acompañado de complementos. Para comprobarlo, observa los siguientes ejemplos:

\section{Miguel tropezó. $\quad$ Pedro pasea con Raquel todos los días por el parque. $\checkmark \quad V+$ complemento + complemento + complemento \\ SV predicado SV predicado}

Recuerda que el núcleo puede estar formado por una perifrasis verbal (un verbo auxiliar conjugado + un infinitivo, un gerundio o un participio):

Ellos van a venir a la fiesta.

perifasis + complemento verbal

\section{Compleis en for suadermo}

El núcleo del sintagma verbal es un que puede ir acompañado de

Fuente: Teide (2008, p. 25).

Una actividad como esta no constituye un reto cognitivo y, por tanto, representa un tipo de actividad no significativa e irrelevante, que conduce a un aprendizaje de la gramática meramente mecánico, basado en la sustitución de elementos formales. La enseñanza de la lengua basada en la gramática y, especialmente, en el nivel oración obvia los logros de la lingüística y la didáctica de la lengua en la segunda mitad del siglo XX (FERNÁNDEZ LÓPEZ, 1987; LOMAS; OSORO; TUSÓN, 1993). No ahonda en los significados y mucho menos en su utilidad para el desarrollo de la competencia comunicativa fuera del aula y evidencia la necesidad de conectar lo gramatical con lo semántico y lo pragmático (CAMPS, 2014, p. 10-11; CAMPS, 2014, 2017, p. 26-27; GIAMMATTEO, 2019, p. 8; MILIÁN; RIBAS, 2016, p. 223).

No pasa desapercibido que la organización de los contenidos gramaticales en estos manuales obedece al estudio tradicional de las oraciones en un temario clásico, al centrar el interés individualmente en el nivel oracional (no se establece relación alguna con el texto o discurso), como puede observarse en el siguiente fragmento de un índice (Imagen 3): 
Imagen 3 - Fragmento de un índice analizado

\begin{tabular}{|c|c|c|c|c|c|}
\hline \multirow{8}{*}{$\begin{array}{l}\text { GRAMÁTiCA } \\
\text { La oración gramatical } \\
\text { La oración } \\
\text { Las palabras y los sintagmas } \\
\text { La estructura de la oración } \\
\text { Estructura del sintagma nominal } \\
\text { Estructura del sintagma verbal } \\
\text { Clases de predicados } \\
\text { Los complementos del predicado } \\
\text { verbal } \\
\text { ACTIVIDADES DE CONSOUDACIÓN }\end{array}$} & \multicolumn{3}{|c|}{ GRAMÁTICA } & \multicolumn{2}{|l|}{ CRAMÁTICA } \\
\hline & 21 & $\begin{array}{l}\text { Clases de oraciones simples } \\
\text { Clases de oraciones seguin la }\end{array}$ & 47 & La oración compuesta & 74 \\
\hline & 22 & actitud del hablante o & & $\begin{array}{l}\text { La oración simpley la oración } \\
\text { compuesta }\end{array}$ & 74 \\
\hline & 23 & la modalidad & 47 & Las proposiciones & 74 \\
\hline & 24 & Clases de oraciones según & & La coordinación & 75 \\
\hline & 25 & la naturaleza del predicado & 48 & La subordinación & 76 \\
\hline & 25 & Oraciones activas y pasivas & 49 & La yuxtaposición & 78 \\
\hline & 27 & $\begin{array}{l}\text { Clases de oraciones activas } \\
\text { Clases de oraciones segun su }\end{array}$ & 50 & ACTIVIDADES OE CONSOLIDACION & 79 \\
\hline ACTIVIDADES DE CONSOUDACIÓN & 29 & $\begin{array}{l}\text { estructura } \\
\text { ACTVIDADES DE CONSOUDACOON }\end{array}$ & $\begin{array}{l}51 \\
53\end{array}$ & & \\
\hline
\end{tabular}

Fuente: Teide (2008, índice).

Esto es debido a que, a pesar de que, a partir de la reforma de los años 90, se introdujeron aspectos provenientes de la Lingüística del texto, no se ha hecho más que incrementar la carga de contenidos gramaticales (ZAYAS, 2011, p. 93). Salvo por algunos ejercicios aislados en los que se plantea un atisbo de que el alumno aprenda por descubrimiento, los libros analizados presentan una concepción del aprendizaje donde el alumno no es el protagonista, sino el receptor y mero repetidor de lo que el profesor enseña, y carente de todo tipo de reflexión. No se proponen actividades que fomenten el aprendizaje colaborativo, para favorecer un aprendizaje social, ni tan siquiera en aquellas ocasiones en que parecería oportuno hacerlo. Véase el ejemplo en la Imagen 4 donde acertadamente se propone una actividad de búsqueda de información en la que deben desarrollarse las destrezas escritas:

Imagen 4 - Ejemplo de actividad de búsqueda de información

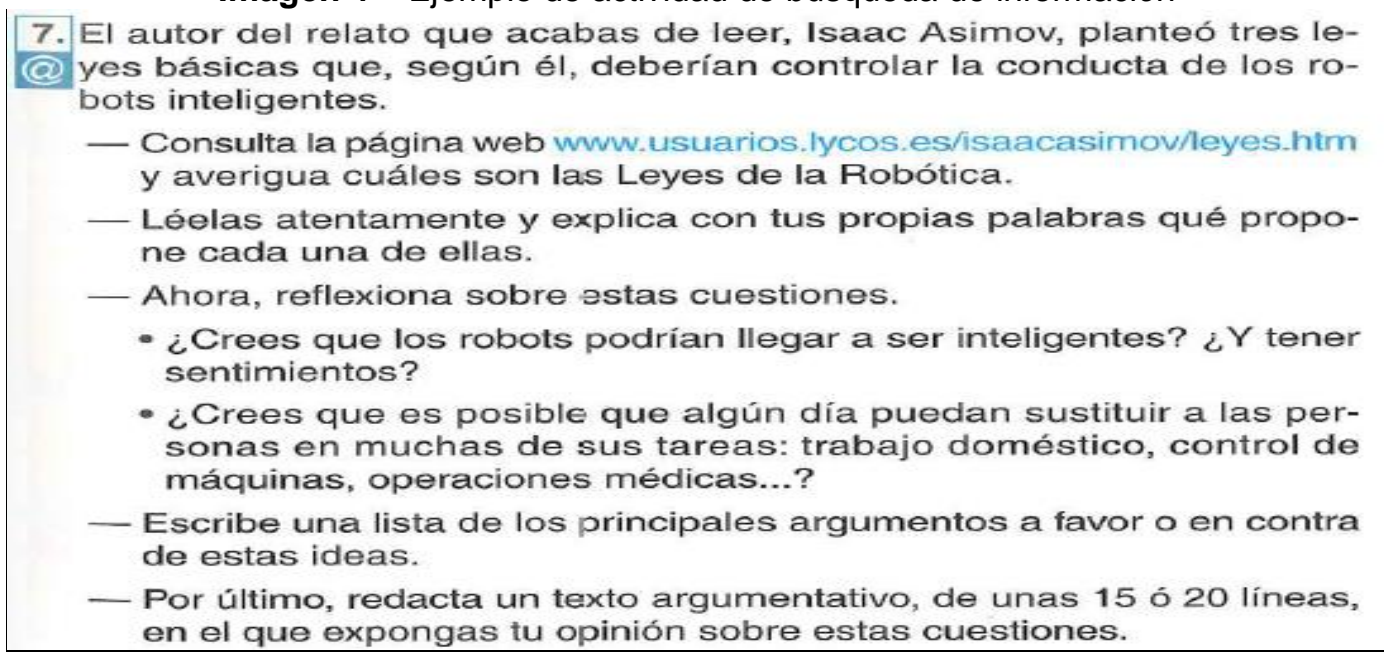

Fuente: Guadiel-Edebé (2008, p. 31).

Educ. Form., Fortaleza, v. 5, n. 3, e2891, set./dez. 2020

DOI: https://doi.org/10.25053/redufor.v5i15set/dez.2891

https://revistas.uece.br/index.php/redufor/index 
Sin embargo, se desaprovecha la oportunidad para el desarrollo de las destrezas orales mediante la interacción entre los alumnos. Todas las instrucciones que se dan conducen a un trabajo individual ajeno a la interacción, como puede apreciarse en el uso de la segunda persona del singular. Dicha interacción es la que puede llevar al alumnado a reflexionar sobre el funcionamiento de la lengua (MILIÁN; RIBAS, 2016, p. 223).

La terminología que se utiliza en las instrucciones de los ejercicios es tan importante para determinar la metodología que se emplee en clase - trabajo cooperativo o individualizado - como para fomentar un aprendizaje basado en la clasificación de elementos o, por el contrario, en la indagación sobre el funcionamiento de la lengua. El uso constante de la segunda persona del singular - y no del plural - en las instrucciones predispone a un trabajo del alumno concentrado en sí mismo. $\mathrm{Si}$, en lugar de instrucciones en las que aparezcan verbos como comentar, discutir, argumentar, inventar, contar, describir, investigar, comparar, etc. - con los que se incita al alumno a usar la lengua y confrontar sus opiniones con otros, como muy bien apunta Barriga (2011, p. 83) -, se usan verbos como clasificar, identificar, señalar, completar, etc., la interacción se confía a la buena voluntad del docente, que debe saber darle otro sentido a las actividades y reconducirlas hacia un plano comunicativo y reflexivo. En los libros de nuestra muestra abundan instrucciones de este último tipo.

Ninguno de los manuales analizados plantea actividades como estrategias para una tarea final de creación textual en la que se haga patente la integración de la sintaxis dentro de un nivel textual en el que se deje de trabajar la oración como elemento aislado del contexto (GIAMMATTEO, 2019, p. 15). Sí, hay algunos de ellos que presentan pequeñas tareas dentro de la lección donde los alumnos deben seguir unas instrucciones para elaborar un producto, generalmente de forma colaborativa. Estas actividades no abundan en los libros, pero, cuando aparecen, por su presencia aislada, tampoco sirven al estudiante como práctica para desarrollar paulatinamente una serie de destrezas que le lleven a incrementar el nivel de dificultad.

Veamos en la Imagen 5 un tipo de actividad que sí está en la línea de lo que creemos que es útil para un aprendizaje comunicativo de la lengua. En él los alumnos tienen que trabajar en equipo para crear un texto, operando así con las cuatro destrezas para discutir sobre qué y cómo hacerlo, escribirlo, corregirlo y, posteriormente, exponerlo: 


\section{EDUCAÇÃO \& FORMAÇÃO \\ Revista do Programa de Pós-Graduação em Educação \\ da Universidade Estadual do Ceará (UECE)}

Imagen 5 - Ejemplo de actividad

El trabajo de un investigador o de un grupo de investigadores tiene éxito si se comunica a la sociedad. Cualquiera que sea el tipo de investigación, la presentación de los resultados se hace conforme a unas normas que permiten estructurar la forma y el contenido.

\section{APRENDIZAJES Y RIESGOS}

Domingo Comas

1. Estudios

- En los últimos años se ha producido una importante inflexión en la dinámica escolar de los jóvenes, se han mantenido las tasas de escolarización en las edades y los niveles obligatorios, pero han disminuido en las posobligatorias.

- Al mismo tiempo, se ha incrementado el fracaso escolar. Como consecuencia, la capacidad del sistema para retener a los jóvenes ha disminuido drásticamente.

Evolución de la proporción de estudiantes en la población juvenil

$\begin{array}{lll}1984(43 \%) & 1992(54 \%) & 2000(49 \%) \\ 1988(51 \%) & 1996(55 \%) & 2004(45 \%)\end{array}$

Fuente: Serie Informes luventud en España

2. Consumo

- Los jóvenes adoptan dos modelos de consumo diametralmente opuestos según su vinculo con la familia de origen. Los emancipados dedican la mayor parte de sus ingresos a su mantenimiento, en especial vivienda, gastos del hogar, alimentación y transporte, mientras que los no emancipados los dedican esencialmente a ocio, viajes y transportes (coche).

- La relación entre ambos modelos de consumo, la edad y los ingresos resulta más compleja de lo esperado al depender de variables como emparejamiento y estilo de proyecto de vida.

Los cinco deseos no satisfechos más relevantes por edad

\begin{tabular}{lllll}
\hline & $\mathbf{1 5}-17$ & $\mathbf{1 8 - 2 0}$ & $\mathbf{2 1 - 2 4}$ & $\mathbf{2 5 - 2 9}$ \\
\hline Comprar una moto & 16,1 & 3,5 & 0,9 & 0,2 \\
Comprar un coche (y carné) & 8,4 & 22,2 & 12,8 & 7,9 \\
Comprar una casa & 4,9 & 12,9 & 23,1 & 28,9 \\
Viajar & 16,5 & 22,8 & 23,0 & 22,6 \\
Ser independiente & 1,4 & 3,7 & 4,3 & 3,8 \\
\hline
\end{tabular}

Lengua. Se emplea un registro idiomático adecuado. Por tanto, hay que usar palabras exactas $y$ un léxico formal.

Fuente: IIE 2004

<www.e-sm.net//cl4eso2>

Elementos visuales. Para ayudar a la objetividad de la información, se pueden añadir gráficos, imágenes, tablas o cualquier tipo de material ilustrativo.

\section{Escribimos un informe}

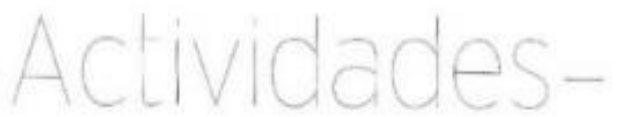

Vamos a realizar un informe sobre el compromiso y los hábitos ecológicos de nuestro curso y de nuestros profesores. Para realizarlo, vamos a seguir los siguientes pasos teniendo como modelo la página web www.frenaelcambioclimatico.org.

A En grupos de cinco, prepararéis un cuestionario sobre las acciones cotidianas con las que contribuimos a frenar el cambio climático y se lo pasaréis a diez compañeros y dos profesores.

B A partir del análisis de los datos obtenidos, redactaréis vuestras conclusiones sobre el grado de compromiso que los alumnos y profesores de $4 .^{\circ}$ ESO tienen ante la necesidad de frenar el cambio climático.

C Exponéis vuestro trabajo. Para ello, debéis emplear gráficos, ilustraciones, vídeos... y entre todos decidis cuáles son las cinco ecoprácticas que vais a poner en marcha.

Fuente: SM (2011, p. 49).

Educ. Form., Fortaleza, v. 5, n. 3, e2891, set./dez. 2020

DOI: https://doi.org/10.25053/redufor.v5i15set/dez.2891

https://revistas.uece.br/index.php/redufor/index 
Como vemos, la mayor parte de los contenidos analizados en estos libros de texto no responden a una enseñanza comunicativa de la lengua. Contrariamente, la gramática aparece aislada del resto de contenidos, otorgándosele, por tanto, el papel de saber teórico que ha recibido en metodologías docentes tradicionales y aislando la oración del resto de niveles lingüísticos.

Otro de los aspectos interesantes que sirve para comprobar cómo fomentan los libros la reflexión lingüística es el análisis de las actividades propuestas para trabajar el error. Y, en tal caso, hemos observado pocas actividades encaminadas a este fin, que una vez más operan exclusivamente en un ámbito descontextualizado donde no se trabaja la oración dentro del texto, como el caso de la Imagen 6:

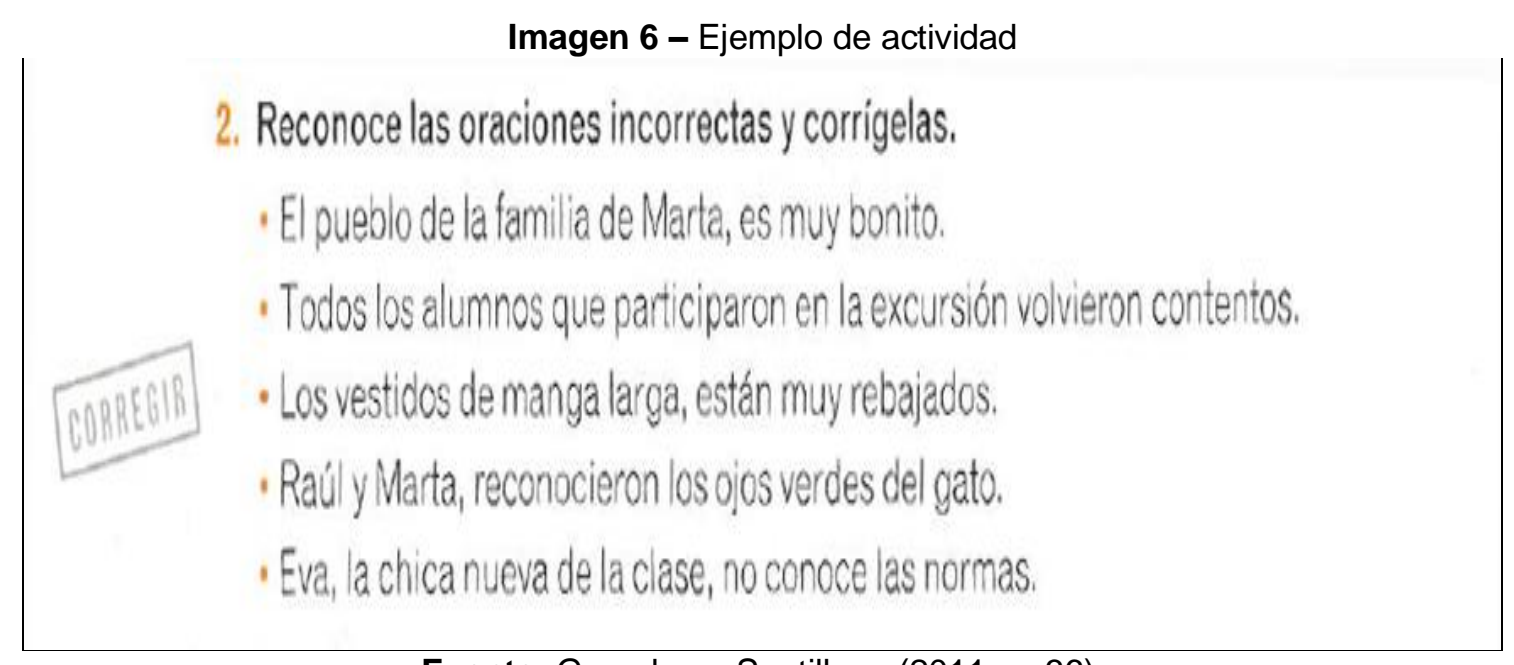

Fuente: Grazalema Santillana (2011, p. 36).

Por último, en la Tabla 2 establecemos una comparativa de los diferentes libros de texto, en la que recopilamos todos los aspectos que hemos tenido en cuenta para el análisis de las actividades propuestas por los manuales mediante una rúbrica de evaluación:

Tabla 2 - Aspectos considerados en la comparativa de libros de texto

\begin{tabular}{|c|c|c|c|c|c|c|c|c|c|}
\hline \multirow{2}{*}{ Ítem } & \multicolumn{9}{|c|}{ Editorial $^{2}$} \\
\hline & 1 & 2 & 3 & 4 & 5 & 6 & 7 & 8 & 9 \\
\hline 1. Las actividades son relevantes y significativas & & & & & & & & & \\
\hline 2. Las actividades fomentan el aprendizaje colaborativo & & & & & & & & & \\
\hline
\end{tabular}

2 1: Oxford; 2: Algaida; 3: Guadiel-Edebé; 4: Teide; 5: Casals; 6: SM; 7: Grazalema-Santillana; 8: Bruño; 9: Edelvives. Color rojo: siempre; color naranja: casi siempre.

Educ. Form., Fortaleza, v. 5, n. 3, e2891, set./dez. 2020 DOI: https://doi.org/10.25053/redufor.v5i15set/dez.2891 https://revistas.uece.br/index.php/redufor/index 
Tabla 2 - Aspectos considerados en la comparativa de libros de texto

(conclusión)

\begin{tabular}{|c|c|c|c|c|c|c|c|c|c|}
\hline \multirow{2}{*}{ Ítem } & \multicolumn{9}{|c|}{ Editorial } \\
\hline & 1 & 2 & 3 & 4 & 5 & 6 & 7 & 8 & 9 \\
\hline Propone actividades de síntesis para trabajar desde el error & & & & & & & & & \\
\hline $\begin{array}{l}\text { 4. Las actividades están planteadas para facilitar y promover la } \\
\text { comprensión escrita }\end{array}$ & & & & & & & & & \\
\hline Las actividades favorecen la producción escrita & & & & & & & & & \\
\hline Hay recursos audiovisuales que facilitan la comprensión oral & & & & & & & & & \\
\hline Las actividades promueven la interacción oral & & & & & & & & & \\
\hline Las actividades promueven un uso comunicativo de la lengua & & & & & & & & & \\
\hline 9. Hay actividades que integran las cuatro destrezas & & & & & & & & & \\
\hline $\begin{array}{l}\text { 10. Las actividades están planteadas como estrategias para una tarea } \\
\text { final de creación textual }\end{array}$ & & & & & & & & & \\
\hline 11. La terminología morfosintáctica sigue un criterio lógico y unitario & & & & & & & & & \\
\hline $\begin{array}{l}\text { 12. Las actividades vienen planteadas desde un enfoque deductivo } \\
\text { (planteamiento del concepto más actividades de verificación por } \\
\text { parte del alumnado) }\end{array}$ & & & & & & & & & \\
\hline
\end{tabular}

Fuente: Elaboración propia (2020).

Como se observa, ninguno de los manuales analizados destaca especialmente por cumplir los objetivos propuestos en la legislación. A pesar de que, a partir de la reforma en el sistema educativo español, surgida en los años 90 , se produce ya un claro cuestionamiento de la identificación entre enseñanza de la lengua y enseñanza de la gramática, nuestro análisis de los manuales docentes corrobora que, pese a esas prescripciones, en la práctica existen escasos cambios en los currículos docentes para la materia de lengua: primero, porque muchos de estos se corresponden con aspectos puramente gramaticales (por ejemplo, el concepto de oración aquí analizado sigue siendo una materia ineludible y vertebradora en todas las programaciones); en segundo lugar, porque en estos manuales se siguen planteamientos clásicos propios de las corrientes lingüísticas formales, relacionando el conocimiento de la lengua con la estructura interna de la misma, hasta el punto de que muchos de los contenidos, actividades y aspectos doctrinales de estos manuales son coincidentes con los encontrados en gramáticas escolares y no escolares del siglo XVIII y XIX, por ejemplo, las propias de la Academia.

\section{Conclusiones}

Con escasas modificaciones, los manuales analizados en nuestro trabajo plantean tímidos avances respecto a la teoría que, desde principios del siglo XX, aparece 
en los libros de gramática de la Academia y se limitan, en todos los casos, a exponer una extensa clasificación de oraciones y fenómenos gramaticales, con sus correspondientes ejemplos y actividades.

No existe ni una verdadera integración de estos contenidos con el resto tampoco un cuestionamiento acerca de su validez y funcionamiento en el desarrollo del alumnado para su capacidad de comunicar y utilizar mejor la lengua en su vida diaria. Todo ello nos pone de relieve la escasa evolución metodológica y conceptual que la clase de lengua y sus contenidos han experimentado en el ámbito didáctico. Los manuales utilizados no responden, en su mayoría, a las expectativas reflejadas en las leyes educativas españolas de las últimas décadas ni a la finalidad que los propios currículos deben cumplir como elementos válidos para la adquisición de competencias dirigidas al uso de la lengua en la actividad social.

El estudio realizado nos da una muestra de cómo los libros de textos no han supuesto el cambio que se presuponía para el estudio de la lengua en el aula y, específicamente, para los contenidos gramaticales. Por lo general, su metodología no cumple con las condiciones para fomentar un aprendizaje significativo de la lengua donde el alumno sea el centro del proceso y pueda llegar a ser consciente de cómo utilizarla con paulatina independencia y aplicación fuera del aula. El análisis concreto de la oración y su persistencia en las programaciones docentes nos da, además, buena muestra de la importancia que todavía hoy se le otorga a esta unidad como punto clave del análisis gramatical; este elemento no permite hacer ver al alumnado el papel fundamental que la gramática ocupa en la construcción del discurso lingüístico. Los ejercicios propuestos suelen estar desprovistos de toda referencia al contexto y no hacen más que perpetuar la condición del nivel oración de protagonista principal de los programas de la asignatura de lengua. Este hecho fomenta la permanencia de la cultura de enseñanza y aprendizaje de la lengua que se impuso en los planes de estudio del siglo $\mathrm{XX}$, olvidando todos los logros obtenidos en la lingüística en la segunda mitad de dicha centuria. Esto no ayuda a que el profesorado encuentre las herramientas adecuadas para integrar la gramática en una enseñanza comunicativa y eficaz.

Ante estos argumentos surge la cuestión eterna: ¿es el libro de texto la herramienta que se debería convertir en catalizadora del necesario cambio metodológico? O, por el contrario, ¿es un corsé tan ceñido que no permite a los 
docentes la flexibilidad necesaria para afrontar ese cambio? Responder a estas preguntas puede darnos la clave de cuál es el papel que deben desempeñar tanto los manuales docentes como el profesorado en un futuro para mejorar no solo la percepción del alumno ante la gramática, sino también su rendimiento funcional en el desarrollo de los individuos, esto es, en la formación de personas que usan la lengua con corrección y eficacia en su vida cotidiana.

\section{Referencias}

BARRIGA, R. Del diálogo a la argumentación. Entre discursos y ejercicios en los libros de enfoque comunicativo. In: BARRIGA, R. (Ed.). Mitos y realidades del desarrollo lingüístico de la escuela: una fotografía de los libros de español del enfoque comunicativo. México, DF: Colegio de México, 2011. p. 69-104.

CAMPS, A. Enseñar gramática: el verbo. In: CAMPS, A.; RIBAS, T. (Coord.). El verbo y su enseñanza: Hacia un modelo de enseñanza de la gramática basado en la actividad reflexiva. Barcelona: Octaedro, 2017. p. 17-64.

CAMPS, A. Hacia una renovación de la enseñanza de la gramática. Lenguaje y Textos, Valencia, v. 40, p. 7-18, 2014.

ESPAÑA. Real Decreto 1631/2006, de 29 de diciembre, por el que se establecen las enseñanzas mínimas correspondientes a la Educación Secundaria Obligatoria. Ministerio de Educación y Ciencia. Gobierno de España. Boletín Oficial del Estado, Madrid, n. 5, 2007.

FERNÁNDEZ LÓPEZ, S. Didáctica de la gramática. Teorías lingüísticas. Sistema de la lengua. Madrid: Narcea, 1987.

FERRER, M. La función del libro de texto en la clase de lengua. Textos de Didáctica de la Lengua y la Literatura, Barcelona, v. 69, p. 51-59, 2015.

GARCÍA FOLGADO, M. J. La historia de la enseñanza de la gramática: reflexiones sobre un campo de investigación. Lenguaje y Textos, Valencia, v. 40, p. 63-72, 2014.

GIAMMATTEO, M. La combinación de oraciones en la enseñanza de la lengua. Lenguaje y Textos, Valencia, v. 50, p. 7-18, 2019.

GIETZ, F. Enseñanza de la gramática y libros de texto: tratamiento del contenido oración. Quintú Quimün, Neuquén, v. 3, p. 1-20, 2019.

GÓMEZ ASENSIO, J. J. Los principios de las gramáticas académicas (1771-1962). Frankfurt am Main: Peter Lang, 2011. 
GUTIÉRREZ ORDÓÑEZ, S.; GAVIÑO RODRÍGUEZ, V. Trescientos años de la fundación de la Real Academia Española: de sus orígenes al siglo XXI. In: CALERO, M. L. et al. (Ed.). Métodos y resultados actuales en Historiografía de la Lingüística. Münster: Nodus, 2014. p. 325-348.

JIMÉNEZ FERNÁNDEZ, R. La gramática en los manuales de la ESO: actividades sobre morfosintaxis. Cauce: Revista Internacional de Filología, Comunicación y sus Didácticas, Sevilla, v. 34-35, p. 231-255, 2011.

LOMAS, C.; OSORO, A.; TUSÓN, A. Ciencias del lenguaje, competencia comunicativa y enseñanza de la lengua. Barcelona: Paidós, 1993.

MARTíN ROJO, I. Escuela y diversidad lingüística y cultural. In: ROJO, L. M. (Ed.). ¿Asimilar o integrar?: dilemas ante el multilingüismo en las aulas. Madrid: Ministerio de Educación, Cultura y Deporte, 2003. p. 13-63.

MILIÁN, M.; RIBAS, T. La reflexión metalingüística y la gramática. In: PALOU, J.; FONS, M. (Coord.). Didáctica de la Lengua y la Literatura en Educación Primaria. Madrid: Síntesis, 2016. p. 213-226.

RAE - Real Academia Española. Compendio de la gramática de la lengua castellana, dispuesto por la Real Academia Española, para la segunda enseñanza, Madrid: Imprenta Nacional, 1857a.

RAE - Real Academia Española. Compendio de la gramática de la lengua española dispuesto para la segunda enseñanza. Bilbao: Madrid: Barcelona: Espasa-Calpe, 1931.

RAE - Real Academia Española. Compendio de la gramática de la lengua española, dispuesto para la segunda enseñanza. Barcelona: Espasa-Calpe, 1949.

RAE - Real Academia Española. Epítome de la gramática de la lengua castellana, dispuesto por la Real Academia Española para la primera enseñanza elemental. Madrid: Imprenta Nacional, 1857b.

RAE - Real Academia Española. Epítome de la gramática de la lengua española para la primera enseñanza. Zaragoza: Heraldo de Aragón, 1938.

RAE - Real Academia Española. Gramática de la lengua castellana. Madrid: D. Joachin de Ibarra, 1771.

RAE - Real Academia Española. Gramática de la lengua castellana. Madrid: Imprenta Nacional, 1858.

RAE - Real Academia Española. Gramática de la lengua castellana. Madrid: Imprenta Nacional, 1862. 
RAE - Real Academia Española. Gramática de la lengua castellana. Madrid: Imprenta Nacional, 1864.

RAE - Real Academia Española. Gramática de la lengua castellana. Madrid: Imprenta Nacional, 1865.

RAE - Real Academia Española. Gramática de la lengua castellana. Madrid: Imprenta Nacional, 1866.

RAE - Real Academia Española. Gramática de la lengua castellana. Madrid: Imprenta de Miguel Ginesta, 1867.

RAE - Real Academia Española. Gramática de la lengua castellana. Madrid: Imprenta y Estereotipia de M. Rivadeneyra, 1870.

RAE - Real Academia Española. Gramática de la lengua castellana. Madrid: Perlado, Páez y Compañía (Sucesores de Hernando), 1917.

RAE; AALE - Real Academia Española; Asociación de Academias de la Lengua Española. Nueva gramática de la lengua española. Madrid: Espasa, 2009.

RIBAS, T. (Coord.). Libros de texto y enseñanza de la gramática. Barcelona: Graó, 2010.

UNAMUNO, M. Discurso en los juegos florales de Almería: 27 de agosto de 1903. Obras Completas, Tomo VII. Madrid: Afrodisio Aguado,1958a. p. 568-588.

UNAMUNO, M. La enseñanza de la gramática: conferencia dada en Bilbao el 11 de agosto de 1905, con motivo de la exposición escolar. Obras Completas, Tomo VII. Madrid: Escélicer, 1958b. p. 632-653.

ZAMORA VICENTE, A. Historia de la Real Academia Española. Madrid: Espasa Calpe, 1999.

ZAYAS, F. El lugar de la gramática en la enseñanza de la lengua. In: RUIZ BIKANDI, U. (Coord.). Lengua Castellana y Literatura: investigación, innovación y buenas prácticas. Barcelona: Graó, 2011. p. 91-106.

\footnotetext{
Antonio Gutiérrez Rivero, Universidad de Cádiz (UC), Departamento de Didáctica de la Lengua y la Literatura

iDhttp://orcid.org/0000-0001-6223-2390

Licenciado en Filología Hispánica y doctor en Didáctica de la Lengua y la Literatura. Profesor sustituto interino en el Departamento de Didáctica de la Lengua y la Literatura de la UC. Su línea de investigación principal se centra en la enseñanza de la lengua con especial énfasis en la enseñanza de la gramática. Cuenta con una amplia experiencia docente tanto en la universidad como en la enseñanza de español para extranjeros, Secundaria y Bachillerato. Ha participado en congresos de Enseñanza de Español para Extranjeros y Didáctica de la Lengua y la Literatura y es autor de artículos y capítulos de libro dentro de esos dos ámbitos.

Contribución de autoría: Recopilación y análisis de datos, redacción y revisión final.

E-mail: antoniogutierrez.rivero@uca.es
}

Educ. Form., Fortaleza, v. 5, n. 3, e2891, set./dez. 2020

DOI: https://doi.org/10.25053/redufor.v5i15set/dez.2891

https://revistas.uece.br/index.php/redufor/index 


\begin{abstract}
Victoriano Gaviño Rodríguez, Universidad de Cádiz (UC), Departamento de Filología
ii(Dhttps://orcid.org/0000-0002-6315-6884

Profesor titular de Lengua Española en la UC. Sus principales líneas de investigación son la gramática descriptiva del español, ámbito en el que ha publicado trabajos relacionados con el estudio de fenómenos sintácticos del español actual (causa, finalidad, partículas discursivas, etc.) y la historiografía lingüística, donde desarrolla en los últimos años una intensa labor investigadora en relación con la gramaticografía española y el estudio de las ideas lingüísticas en la prensa del siglo XIX. Ha realizado estancias investigadoras y docentes en numerosas universidades extranjeras (Princeton University, Freie Universität Berlin, University College Dublin, Helsingin Yliopisto, Ruprecht-Karls-Universität Heidelberg, Libera Università degli studi Internazionali di Roma, Göteborgs Universitet, Masarykova univerzita, Universitetet i Bergen, Universidade de Lisboa, Uniwersytet Jagiellonski, Università Ca' Foscari Venezia, etc.) y cuenta con una extensa trayectoria docente, así como amplia experiencia en el terreno de la enseñanza del español y la formación de profesores. Actualmente es director del Departamento de Filología de la UC y director académico del curso de experto Civilización, Literatura y Lengua Españolas, impartido para estudiantes de la University of Washington en el marco del NW-Cadiz Program.

Contribución de autoría: Discusión teórica, redacción y revisión final.

E-mail: victoriano.gavino@uca.es
\end{abstract}

Editora responsable: Lia Machado Fiuza Fialho

Pareceristas ad hoc: Mário Azevedo y Hugo Heredia Ponce

\title{
Cómo citar este artículo (ABNT):
}

GUTIÉRREZ RIVERO, Antonio; GAVIÑO RODRÍGUEZ, Victoriano. La huella de la Real Academia Española en manuales de enseñanza de la lengua para la Educación Secundaria. Educ. Form., Fortaleza, v. 5, n. 3, p. 1-21, 2020. Disponble en: https://revistas.uece.br/index.php/redufor/article/view/2891.

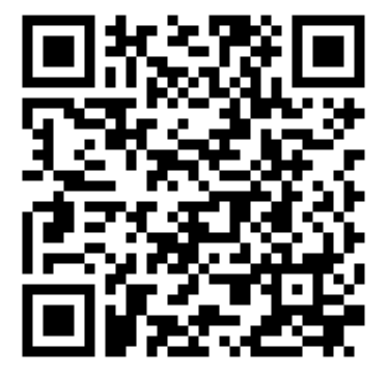

Recibido el 11 de marzo de 2020.

Aceptado el 19 de mayo de 2020.

Publicado el $1^{\circ}$ de junio de 2020.

Educ. Form., Fortaleza, v. 5, n. 3, e2891, set./dez. 2020

DOI: https://doi.org/10.25053/redufor.v5i15set/dez.2891

https://revistas.uece.br/index.php/redufor/index 